\title{
A Better Approach by Management in Drug Testing
}

\author{
George E. Stevens, ${ }^{1}$ Carol D. Surles, ${ }^{2}$ and Faith W. Stevens ${ }^{3}$
}

Discussed here are a number of drug abuse and drug testing issues. This article presents an overview of current developments in the area of drug testing in the workplace. There is an analysis of legislation, federal and state court decisions, and key legal arguments. These decisions and arguments are discussed in the context of employee rights and responsibilities. Also presented are the legal and ethical aspects of drug testing in the workplace. The authors make a case for a rehabilitative rather than a punitive approach to employee drug abuse.

KEY WORDS: drug abuse; drug abusers-personnel policies; employers' liability; problem employees; medical and physical examinations; supervisors-responsibilities.

\section{INTRODUCTION}

Drug abuse-the subject now appears in many media: newspapers, magazines, journals, television, and radio. The size of coverage on this topic says that our country is in the midst of a serious problem. This problem has ramifications for all of us. Of particular concern is the impact of drug abuse on those who supply the nation's goods and services.

This article has three purposes. We provide statistics that give an indication of the severity of the drug abuse problem. We identify the responses being made by business to the drug problem. We tell why we believe there is a need to go beyond testing.

Over the past few years, the drug problem has received much attention from business and government leaders. Many studies show that illegal drug use causes an increase in accidents, higher absenteeism, and more health problems (Castro, 1986; Hanson, 1986; Landis, 1986). Employers display a lack of tolerance for those who use illegal drugs (Becker, 1986). Drug and alcohol abuse is a multi-billion-dollar problem for which solutions continue to be both elusive and controversial. Employers and union and public policy leaders continue to struggle with this problem of

\footnotetext{
${ }^{1}$ Department of Management, College of Business Administration, University of Central Florida, Orlando, Florida 32816-0991.

2The Chancellor's Office, The University of Michigan-Flint, Flint, Michigan 48502.

${ }^{3}$ Department of Business Administration, University of Maryland-Eastern Shore, Princess Anne, Maryland 21853 .
} 
proliferation in the use and abuse of various substances. Why has the problem grabbed the attention of such a diverse group? The statistics cited in the next paragraph provide the answer.

Federal experts estimate that there are 22 million marijuana users, 12 million alcoholics, 10 million pill users, and 6 million cocaine users. According to the National Institute of Drug Abuse, as much as $65 \%$ of the people now entering the work force have used illegal drugs. Also, from $10 \%$ to $23 \%$ of all U.S. workers are getting high on the job (NIDA, 1986). How widespread a problem is substance abuse in the workplace itself? Estimates such as those just cited do not reveal actual use on the job. However, a recent survey done by a New Jersey hotline reported striking indications of prevalence among its employed clients. Seventy-five percent of avowed drug users admitted using drugs on the job. Sixty-four percent admitted that they had sold drugs on work premises. Eighteen percent admitted they had had a drug-related accident. Sixty-nine percent said drug use impaired their job performance. Eighteen percent admitted they had stolen from their employer to purchase drugs (Castro, 1986).

When employees use drugs and alcohol in the workplace, a number of problems are likely to follow. Dr. Daniel Lanier Jr., associate director of the employee assistance programs at General Motors, provides a profile of an abuser. The abuser functions at slightly more than half of normal capacity. He or she is absent up to 16 times more than the average employee. The abuser has an accident rate that is four times greater than other employees. He or she uses a third more sickness and accident benefits than other employees. One GM study found the abuser's use of these benefits to be 10 to 12 times greater than other employees. Also, the drug abuser has five times more worker compensation claims, and is responsible for $47 \%$ of industrial injuries and fatalities (Koterba, 1986).

\section{THE RESPONSE TO THE PROBLEM - DRUG SCREENING}

American business, as a result of a growing national concern and the economic and social threats attributable to drug abuse, has begun a corporate war on drugs. The cannon in this corporate war is urinalysis. The justification for screening for drugs may be general - in response to widespread publicity about the problem. However, a local case may have aroused concern or a company may be following the lead of other companies. The increased use of drugs in our society has given rise to the implementation of testing procedures, especially urinalysis screening (Chan \& Gates, 1987; Hanson, 1987; Ward, 1986). Roberts (1986) provides the following examples:

- More than $30 \%$ of Fortune 500 companies require applicants or employees to provide blood or urine samples for traces of illegal drugs.

- The President's Commission on Organized Crime wants all federal employees and employees of government contractors to take tests for drug use.

- President Reagan issued Executive Order 12564 imposing mandatory testing for all federal employees in sensitive positions.

- The police departments of many municipalities, including New York, Boston, and Newark, N.J., have instituted mandatory drug testing of employees. 
- The military, during the 1985 fiscal year, spent $\$ 47.6$ million for three million tests for drug abuse.

- According to estimates, $\$ 80$ million a year is spent on drug testing in the United States, and this figure will double by 1990.

According to Masi and Burns (1986), industry uses three types of urinalysis screening for drugs. In preemployment screening, companies test all applicants or selected applicants before employment. Often this screening occurs in conjunction with a preemployment physical examination. Some companies inform applicants ahead of time that there will be a drug screen and other employment tests. Organizational representatives gather information about any medication being taken, the reason for the medication, and the dosage. Random urinalysis is a method that involves the selection of a significant number of employees. A random sample of employees is drawn by using a statistical approach. This type of screening occurs at various times throughout the year. An employee is not chosen for testing in a predictable fashion. As a member of a particular job category or job level, the employee is eligible for screening at any time. The final method of urinalysis screening is "for cause." When done, supervisors or employers require "for cause" testing for a particular employee who is impaired by drugs or alcohol or unfit for work. This method commonly occurs after an accident or observable change in behavior of an employee.

\section{MORAL, ETHICAL, AND OTHER ISSUES}

Judge H. Lee Sarokin of the U.S. District Court in Newark, N.J., in ruling that mandatory urine testing of government employees was an unconstitutional invasion of privacy, had this to say:

The threat posed by widespread use of drugs is real, the need to combat it manifest.... [I]t is important not to permit fear and panic to overcome our fundamental principles and protections. .. . The invidious effects of such mass, roundup urinalysis is that it casually sweeps up the innocent with the guilty and willingly sacrifices each individual's Fourth Amendment rights in the name of some large public interest. (Morris, 1986).

In the judgment of Mark A. Rothstein, law professor at the University of Houston, testing in the workplace is not going to stop drugs. He feels the issue of testing has moved the discussion away from the real problem.

Testing in the workplace raises a number of other issues. Whether workers have the right to say no to a drug test request is a question that courts routinely confront. We do know that the Constitution does not provide the protection that many workers think it does. For example, the Constitution prohibits unreasonable searches and seizure. Also, it requires due process. However, these clauses apply only to governmental acts. Invasion of the right to privacy is not absolutely guaranteed. Such protection does exist in certain states, while elsewhere the legal basis is unclear. Public employees have certain rights, based for the most part on the U.S. Constitution. Private sector employees must depend on various state and local regulations and common law to assert challenges to drug testing programs. Bickerton (1986) asks a more fundamental question: Are present methodologies, particularly urinalysis, so intrusive and so error prone that they should be disallowed by law? 
Serious questions are being raised about the validity and reliability of these tests. Opponents question the ability of laboratory workers to interpret test results accurately (Gampel \& Zeese, 1985; Bogdanich, 1987; Hanson, 1986; Spitzer, 1986). Studies done by the Centers for Disease Control, the Department of Defense, the Center for Human Toxicology, and the New Jersey Department of Corrections revealed high error rates. These error rates exceed the error rates found in manufacturers' literature. For example, a well-known test is the EMIT test. The manufacturer, Sylva, acknowledges a $5 \%$ error rate. However, results of the studies cited above uncovered error rates ranging from $11 \%$ to $100 \%$ (Spitzer, 1986).

A discussion of one study might clarify the nature of the problem. A careful 10-year blind study conducted by the federal Centers for Disease Control (CDC) suggests that certain laboratories may be deficient. As reported in the Journal of the American Medical Association (April 26, 1985), 13 independent laboratories that perform drug analysis received urine samples known to be either drug-free or drug contaminated. Incorrect reports of drug presence (false positives) from certain laboratories were as high as $66 \%$ in tests for the presence of methadone. The same laboratories submitted reports with error rates as high as $37 \%$ in tests for amphetamines. The Centers for Disease Control judged only one laboratory to have povided "acceptable performance" in testing for barbiturates. This performance level is defined as $80 \%$ correct responses. Similar results were obtained in testing for cocaine. The $80 \%$ standard was met by only one laboratory (Spitzer, 1986).

In addition to the issue of inaccuracy, opponents of drug testing believe that other problems and limitations exist. For example, they question a focus on illicit drugs that ignores the larger group of impaired workers who abuse legal drugs. The legal drugs cited include prescribed medicine, alcohol, and over-the-counter medications. Opponents say the tests fail to measure drug impairment. The Bureau of National Affairs report mentioned earlier states that absent a walk-the-line test, there is no current means of determining impairment. Drug tests range from least-invasive (e.g., breathalizers), to slightly invasive (e.g., saliva and urine samples), to invasive (e.g., stomach pumping). The resistance of employees, unions, governmental agencies, labor arbitrators, and courts to these tests relates directly to the degree of invasiveness of the tests.

Opponents make other claims. They feel that urine tests do not reveal drugs present in the urine. Instead they reveal metabolites remaining from past drug use. The presence of metabolites in the urine is of limited significance. Testing the urine of people involved in an accident will not show if anyone was under the influence of any drug when the accident occurred. The term "drug testing" therefore is a misnomer. Urine testing is inactive metabolite testing (Zeese, 1987).

Other issues concern opponents. There is the potential for use of drug testing as a tool for discrimination. There is an inability to determine when a drug was taken. The timing or frequency of use cannot be determined from urine tests. Those opposed to testing say that testers ignore the potential of testing to alienate even trusted employees.

\section{EMPLOYER PROTECTION}

Employers believe that they have legitimate reasons for testing their employees. In many instances, the employers' need to test outweighs employees' privacy con- 
cerns. For example, courts look to particular factors in assessing the significance of the employer's interest in testing compared to the rights of the employee. The courts consider a variety of factors, such as the type of job, the specific justification for searching this particular group of individuals, or a demonstrated need to test applicants. Other factors include whether less intrusive measures than testing exist, what role unions played in negotiating a testing program, the validity of the test, the presence of safeguards such as the use of a confirmatory test, and whether the search is effective.

State laws, particularly state criminal statutes, may provide the bases for actions against employees who use drugs which impair their job performance. In some states (e.g., Minnesota and Montana), state or local statutes may explicitly permit testing of employees in certain critical or "safety-sensitive" occupations. For example, correctional officers, public health officials, safety workers, public transportation employees, and nuclear power plant employees are subject to drug testing under various laws. Although most states and municipalities that have statutes covering drug testing focus on limitations on employers, some state statutes are less restrictive. Utah is an example of a state statute under which employers may test employees for a variety of reasons. There is no reasonable suspicion standard. Employers may test both prospective and current employees, and testing is a condition of employment for the former group. Employers test the latter group for reasons such as involvement in an accident or theft, issues involving safety, investigation of possible individual impairment, or negative productivity. Other reasons for testing include performance changes, or questions of the security of property (Shattuck, 1986).

The significance of state laws such as Utah's is the recognition that given appropriate employee protections, circumstances do occur in which employers have a legitimate right to conduct drug testing programs. However, a testing program must have the following components: trained supervision, open communication, fairness, consistency, nondiscrimination, and sound legal advice. The results of the testing program must be reliable and valid. By meeting these stipulations, a company can successfully navigate the legal, ethical, and moral mine field that exists.

\section{LEGAL IMPLICATIONS OF TESTING AT THE FEDERAL LEVEL}

There are many risks in the hiring or continued employment of an individual who is addicted to, dependent upon, or an abuser of drugs. This is an issue of increasing concern to employers. In addition, the employer must be aware of the existence and extent of such circumstances before making an employment decision. Various legal principles affect the employment decision-making process with regard to the acceptance, rejection, or termination of drug and/or alcohol users. Questions concerning the propriety of drug and alcohol screening are most likely to be raised under the requirements of two federal laws. These two laws are Title VII of the Civil Rights Act of 1964 and Title V of the Rehabilitation Act of 1973.

Title VII prohibits employment discrimination on the basis of race, color, national origin, religion, and sex. Employer drug and alcohol screening programs might run afoul of the prohibitions of Title VII when employment decisions based on the information obtained during the screenings adversely affect members of the groups that Title VII seeks to protect, e.g., women and minorities. Similarly, the Rehabilitation Act, broadly stated, prohibits discrimination against the handicapped. Problems arise where an employer declines to hire, chooses to fire, or denies advancement to 
someone who is or the employer believes is physically or mentally incapable of performing the essential tasks of the job at issue. According to Shattuck (1986), many issues are raised under the Rehabilitation Act. Among these are (1) whether the applicant or employee is handicapped; (2) whether the applicant or employee is "qualified" or "otherwise qualified" for employment, promotion, or retention in spite of the handicap; and (3) what types of affirmative action efforts employers undertake with regard to handicapped applicants or employees. Also considered are the steps an employer takes to determine whether an applicant or employee is handicapped.

Shattuck (1986) warns that the use of drug testing procedures is on the rise but employers, especially those in the public sector, should be aware that testing an employee's blood or urine for traces of drugs may constitute an illegal search. Such an unwarranted intrusion on one's right of privacy is in violation of the Fourth Amendment of the Constitution. The U.S. Supreme Court has held that the Fourth Amendment's prohibition against unreasonable search and seizure applies to taking blood from one's body (Schmerber $v$. California, 1966). In addition, the failure to hold a hearing may violate an employee's Fourteenth Amendment due process rights if the basis for an employee's termination was his or her positive urinalysis test.

\section{STATE ISSUES}

States are taking a myriad of approaches to drug testing. These vary from outright bans to testing within liberal guidelines. Forty-nine states and many large cities have enacted legislation similar in scope and coverage to the Rehabilitation Act of 1973. According to a recent report (Beissert, 1987), many state legislatures have just passed or are considering drug testing legislation. The states are Arizona, California, Connecticut, Hawaii, Indiana, Iowa, Maine Massachusetts, Minnesota, Maryland, Mississippi, Nebraska, New Jersey, New York, Oregon, Texas, Vermont, and Wyoming. In most cases, the legislation attempts to address problems with testing (e.g., quality control in labs) while avoiding the central issue of constitutionality of drug testing. Various laws require state licensing of labs with surprise inspection, confidentiality of results, written rules for discipline and including appeal procedures, and a different confirmatory test of all positive results.

At one end of the continuum, the Oregon and Maine proposals would ban testing. In the middle of the road are laws or proposals being considered in Connecticut, Hawaii, Iowa, and Vermont. These regulations allow testing only if the employee's job performance is impaired or is a safety hazard. An independent laboratory conducts the testing and there is allowance for employee rebuttal under the latter proposals. Less strict are state proposals (e.g., Texas, California, Wyoming) and Utah's law, where testing occurs with little or no state intervention. In some state courts, cases are being heard in which plaintiffs allege causes of action for wrongful discharge termination, retaliation for exercise of constitutional rights, or invasion of privacy. Others claim intentional and negligent infliction of emotional distress, loss of consortium, and false imprisonment.

Some states, such as Massachusetts, recognize a right to privacy by statute. Employees tested could assert a cause of action under such a statute. Another area of concern to employers are tort issues. These tort issues include intentional infliction 
of emotional stress, negligent infliction of emotional distress, defamation, wrongful discharge, and invasion of privacy. There are many court cases on these issues (e.g., Payton v. Abbott Labs, 1982; Houston Belt and Terminal Railway v. Wherry, 1976; Lewis v. Dayton Hudson Corp., 1983; and Satterfield v. Lockheed Missiles and Space Co., 1985).

\section{COLLECTIVE BARGAINING}

The National Labor Relations Act (NLRA) requires a unionized employer to bargain with the union over terms and conditions of employment. The unilateral implementation of a term or condition of employment without prior consultation with the union may constitute an unfair labor practice under Section 8(a) (5) of the NLRA. The National Labor Relations Board's General Counsel, Rosemary Collyer, has issued a memorandum setting guidelines for the NLRB's regional office on the handling of drug testing cases. The General Counsel believes that drug testing is a mandatory subject of bargaining. Rather than unilaterally impose a drug testing program, management must bargain in good faith over the issue. The union is permitted to use economic strategies during bargaining over this issue. Less clear is the issue of testing applicants. Also, unionized employers should be aware of employee rights under the Weingarten Rule. The employer must permit the presence of a union representative if so requested at an investigatory interview which the employee reasonably believes may result in the imposition of discipline.

\section{WHERE DO WE GO FROM HERE?}

\section{Is Testing the Way to Go?}

Robert J. Campbell, president of the Alcoholism Council of Greater New York (American Society for Personnel Administration, 1986), acknowledges that drug testing is a reality. However, he believes that most employers are not seizing this opportunity to give people the counsel they need regarding drug issues. Masi and Burns (1986) and AFL-CIO economist and collective bargaining expert John Zalusky agree with Campbell. Masi and Burns (1986) believe some companies are turning to other methods specifically geared to search out the drug user in industry. These writers also believe that the overlooking of EAP professionals as resource people is a significant problem given that "... for most companies, the goal is to terminate, not rehabilitate, employees who test positive for drugs." Zalusky feels that too many companies are testing for drugs "but not dealing with the fundamentals of why there is abuse and how people can be helped." He notes that while some companies have programs where all abusers can get help, others provide EAPs only to those with alcohol problems (Memmoth, 1986).

As Brown (1987) suggests in a recent article, there is a need to look before leaping into a drug screening program. She suggests that employers identify specific, defensible, legal, ethical, and sensitive explanations. Explanations might include: possible 
liability because of failure to detect unfitness for work, the need to weed out high risk individuals in the preplacement process, or declining or erratic performance apparently attributable to employee drug use. Other explanations might be: accidents attributed to drug effects, employee complaints about safety hazards posed by a worker on drugs, and use, sale, or distribution of drugs on company property or time.

In addition, the employer must carefully examine assumptions made about drug testing. The employer might ask a number of questions. Is the drug problem real? Is the drug problem serious enough to justify unusual steps? Is biological screening an effective means to get at the problem? Is this the best method available? Are screening techniques simple, accurate, and essentially problem-free? Have drug screening programs been adequately tested and debugged?

The requirement that employers have defensible reasons for doing drug screening challenges assumptions made about drug screening but does not mean that they should not test for drugs; however, before they decide, they must first do their homework and test their assumptions by asking some difficult questions. What are the company's objectives in establishing a drug screening program? Has the company considered key laws, regulations, contract provisions? Can the employer require employees to submit to drug examinations?

\section{Beyond Testing}

Many writers state unequivocally their belief that testing is not enough (e.g., Masi \& Burns, 1986; Sonnenstuhl \& Trice, 1986). We concur. We would go one step further. We see the recent, precipitous wave of drug testing by many of the nation's employers as the ultimate abdication of management's responsibility to supervise employees or the worst blow to the present, progressive, and enlightened human reosurces movement. In addition, we believe this approach is a flagrant violation of the Fourth Amendment, which prohibits illegal search. A measure of effective management in the public sector, private industry, and other organizations has long been management's ability to accomplish work through people. This challenge has never been easy; journals on personnel management dating back to the late 1930s are full of case studies related to employee discipline-even instances of alcohol abuse. The outgrowth of many efforts to tackle this and other behavioral problems has been encouraging over the past 50 years - especially in the past 15 years. We have seen socially conscious, sensitive, and sophisticated approaches aimed at alcohol, other drugs, and emotional problems in the workplace. The most widely accepted concept is probably the employee assistance program (EAP) model, which encourages supervisory identification and referral for treatment of behavior problems that interfere with job performance.

This concept (EAP) is free of invasive, demeaning techniques and limits its application only to those aspects of behavior that are rightly within the purview of supervisory responsibility. Even when drug use is confirmed, this concept accords employees the right of choice to refuse treatment and give up their jobs. This approach preserves the employee's dignity. There is widespread agreement among EAP specialists that this approach, although not aimed directly at drug and alcohol abusers for the sake of addressing a serious social problem, actually reaches a large percentage of abusers in quite an appropriate manner. Additionally, EAPs are cost effective (Wiedrick, 1986). 
Surely, neither the current federal administration nor today's employers are so naive that they would propose testing as a national panacea to society's most serious drug problems. Surely, their concerns are realistically focused on ensuring a competent work force. Surely, it is known that drug pushers will not be in large numbers in applicant pools - they are already employed. Furthermore, we believe the heaviest drug abusers have already dropped out of the job market, leaving, among those who do not use drugs, those who still have enough control to avoid taking drugs long enough to present a drug-free specimen at the time they apply for a job.

In spite of the demonstrable cost effectiveness and other benefits of EAPs and a more integrated, systematic, as well as thorough approach to drug abuse in the workplace, most employers seem, until recently, to have ignored the oncoming epidemic. With the blessing of the Reagan Administration, some organizations have experienced anxiety attacks that might predispose our nation to a drug testing era that is sure to be more unhealthy for our American work force than imaginable. Drug testing as a part of preemployment assessment might be analogized to firing a bomb at night at a limited target, not knowing the size nor placement of that target. For those who are subjected to this practice, the insult of it is certain to cause strong feelings and create fallout. Furthermore, Americans have been ingrained with the credo that we must be cautious of quick solutions to problems.

\section{A Better Way}

In our opinion, there is a need to manage drug use in the context of job performance. This requires a serious commitment by chief executive officers to use a more comprehensive strategy in dealing with the problem. CEOs and union officers must work together to see that supervisory and nonsupervisory employees are well trained at all levels. Undergirding this approach is basic respect for and belief in human beings. Job performance in its broadest context includes many elements. The focus should be on employees' physical and emotional readiness to perform their duties when they report to work; thus, monitoring attendance, punctuality, mental attitude, and apparent physical state are fundamental.

A special report developed by the Bureau of National Affairs, Drugs \& Alcohol in the Workplace: Costs, Controls, and Controversies (Bureau of National Affairs [BNA], 1986) is a good guide for the concerned employer. The report includes 14 case studies of employer and union efforts to combat drug and alcohol abuse in the workplace. These in-depth reports show how individual employers and unions are implementing a wide range of approaches. Among these approaches are the following:

- Employee assistance plans to encourage identification and rehabilitation of workers with substance abuse problems.

- Full scale and selective drug testing of applicants and employees.

- Dogs trained to detect drug and alcohol stashes.

- Blanket prohibitions against use of illegal drugs on or off the premises, including Christmas parties.

- Undercover surveillance operations to detect on-the-job drug dealers and purchasers. 


\section{Supervisor and Co-Worker Involvement}

Supervisors and co-workers have a key role to play in making and drug use program work. Each can be part of the solution to the problem by taking certain steps. Using job performance as the focus, supervisors must be aware when an employee is habitually tardy or chronically absent. Supervisors must recognize the individual who reports to work in an unstable condition, one who is frequently glassy-eyed, or one who appears inattentative and disheveled. Each situation requires supervisory attention. Management must deal with such an employee in order to avoid more serious inefficiency and disruption. A supervisor who fails to act in such instances is clearly remiss. Close supervision is necessary for those who make frequent errors, are short-tempered, show inappropriate affect, are accident prone, engage in horseplay, are guilty of excessive scrap loss, waste supplies and material, use profanity on the job, fight, are frequently absent from their work areas, are insubordinate, steal, lie, exhibit bizarre behavior, use drugs and/or alcohol during work hours, or exhibit other disruptive behavior.

Supervision must sensitively convey that management's primary interest lies in accomplishing the work effectively, efficiently, and economically. At the same time an employee presenting problem behavior needs to know that the problem behavior is obvious to management and will not be tolerated. It is facilitative if management can offer referral to treatment agencies if there is substance abuse. It is even more helpful if management has an EAP and a health insurance program that pays part or all of the cost of treatment.

Supervisors assist when they

1. Pay attention to warning signs of drug abuse;

2. Make it clear to everyone that drug use is unacceptable in the workplace;

3. Enforce the company's work standards consistently;

4. Act when an employee's performance or safety becomes a problem;

5. Refuse to inadvertently help an abuser maintain his/her habit.

Co-workers become part of the solution when they

1. Express their concern to a co-worker who is using a drug;

2. Urge the drug abuser to get help for his/her dependency before matters get worse;

3. Discuss the issue with their supervisor if it becomes a problem for them;

4. Refuse to inadvertently help an abuser maintain his/her habit.

The comprehensive approach outlined here, which has a rehabilitative rather than punitive perspective, compels managers to be on the job at all levels and always. It focuses on the appropriate interest of management-specifically, job performance and accomplishment of the work. This approach cannot be characterized as a misguided, naive attempt to solve the nation's drug problem; it is not seen as a precurser to totalitarianism in our nation nor the easy way out for employers. It does not abdicate management's role, and more important, it does not punish citizens who are good and honorable role models.

At present, current federal, state, and local statutes limit to some degree the right of employers to impose drug testing programs on their employees. Employers 
also have rights. For example, employers have a right to assure that their workers are not, because of their impairment, placing themselves or others at risk or failing to do their jobs. Constitutional protections are afforded to the public employee, but less clear are the protections provided to the private employee. He or she must depend on a mixture of federal, state, local, and common law to assert a challenge. Many issues remain unclear. Law in this area will go through an evolutionary process. After additional cases are decided in the courts, the rights and responsibilities of employees will be made clearer.

\section{REFERENCES}

American Society for Personnel Administration (1986, June). Drug abuse solutions elusive, report says. Resource, 7.

American Society for Personnel Administration (1987, February). Workplace drug testing up; further increases are unlikely. Resource, 1-2.

Becker, J. (1986, March 5). More employers testing for drugs. USA Today, B-1.

Beissert, W. (1987, March 24). Drug testing guidelines are considered by states. USA Today, A-2.

Bickerton, R. L. (1986, September-October). Urinalysis: Dilemma of the '80s. EAP Digest 6(6), 27-35.

Bogdanich, W. (1987, February 2). Labs offering workplace drug screens in New York have higher error rule. Wall Street Journal, 18.

Brown, A. (1987, March). To test or not to test. Personnel Administrator, 32(3), 67-70.

Bureau of National Affairs (1986). Drugs and Alcohol in the Workplace: Costs, Controls and Controversies. Washington, DC: BNA.

Castro, J. (1986, March 17). Battling the enemy within. Time 129, 52-59.

Chan, M. M., \& Gates, M. G. (1987, April 3). Worker drug testing gains momentum. USA Today, A1-A2.

Gampel, J. C., \& Zeese, K. B. (1985, Fall). Are employers overdosing on drug testing? Business and Society Review, 73-77.

Hanson, D. A. (1987, March). Company responses to drug abuse from AMA's nationwide survey. Personnel, 40, 44-46.

Hanson, D. J. (1986, June 2). Drug abuse testing programs gaining acceptance in workplace. Chemical and Engineering News 64, 7-14.

Houston Belt and Terminal Railway v. Wherry, 548 S.W.2d 743 (Tex. Civ. App. 1976).

Koterba, A. A. (1986, September-October). GM takes strong stand against drugs. EAP Digest 6(6), $20,72$.

Landis, B. I. (1986, October). Discharging the drug dealer and making it stick. Security Management $30(10)$, 68-71.

Lewis v. Dayton Hudson Corp., 128 Mich. App. 165, 339 N.W.2d 857, 859 (1983).

Masi, D. A., \& Burns, L. E. (1986, September-October). Urinalysis testing and EAPs. EAP Digest 6(6), $37-43$.

Memmoth, M. (1986, November 6). Companies face drug test dilemma. USA Today, B1-B2.

Morris, B. (1986, October 2). Drug tests indicate overdoses of hysteria. Orlando Sentinel, D-1.

National Institute on Drug Abuse (1986, March). Drugs in the workplace. NIDA Capsules. Rockville, MD: NIDA.

Payton v. Abbott Labs, 386 Mass. 540, 437 N.E.2d 171 (1982).

Roberts, T. E. (1986). The Workplace: Critical Issues. Tallahassee, FL.: Florida State University.

Satterfield v. Lockheed Missiles and Space Co., 617 F. Supp. 1359 (D.S.C. 1985).

Schermber v. California, 384 U.S. 757 (1966).

Shattuck, C. (1986, November). Drugs in the workplace: Central issues and guidelines for employer policy. In Roberts, T. E. (Ed.), The Workplace: Critical Issues, CERL Monograph No. 4, pp. 1-32. Tallahassee, FL.: Florida State University.

Sonnenstuhl, W., \& Trice, H. M. (1986, Spring). Lessons from EAPs for drug screening. ILR Report 23(2), 25-29.

Spitzer, A. B. (1986, Spring). Drug screening: Usually unnecessary, frequently unreliable, and perhaps unlawful. ILR Report 23(2), 21-24.

Ward, S. (1986, September 23). Drug tests at work: Crackdown on cocaine. USA Today, A-1,

Wiedrick, L. F. (1986, May). Help workers beat substance abuse. Business Insurance 20, 24.

Zeese, K. (1987, February). Urine testing and the Fourth Amendment. Search and Seizure Report 14(2), 97-104. 